\title{
Lipid-mediated ex vivo gene transfer of viral interleukin 10 in rat lung allotransplantation
}

Hideki Itano, MDa

Bassem N. Mora, MDa

Wanjiang Zhang, MDa

Jon H. Ritter, $M D^{\mathrm{b}}$

Timothy J. McCarthy, $\mathrm{PhD}^{\mathrm{c}}$

Nelson S. Yew, PhD ${ }^{d}$

T. Mohanakumar, $\mathrm{PhD}^{\mathrm{a}}$

G. Alexander Patterson, MDa
From the Division of Cardiothoracic
Surgery, ${ }^{\mathrm{a}}$ Department of Pathology, ${ }^{\mathrm{b}}$
Department of Radiology, ${ }^{\mathrm{c}}$ Washington
University School of Medicine, St Louis,
Mo, and the Genzyme Corporation, ${ }^{\mathrm{d}}$
Framingham, Mass.

Presented at the 2000 Clinical Congress of the American College of Surgeons, October 22-27, 2000, in Chicago, Ill.

This work was supported by National Institutes of Health grant R01 HL 41281 (G.A.P.) and HL 56643 (T.M.) and the Genzyme Corporation. The nitric oxide analyzer was purchased through a grant from the Whitaker Foundation (T.J.M.). H.I. was supported by the Okayama University Medical School.

Received for publication Oct 9, 2000; revisions requested Nov 28, 2000; revisions received Jan 18, 2001; accepted for publication Jan 23, 2001.

Address for reprints: G. Alexander Patterson, MD, 3108 Queeny Tower, One BarnesJewish Hospital Plaza, St. Louis, MO 63110 (E-mail: kellym@msnotes.wustl.edu).

J Thorac Cardiovasc Surg 2001;122:29-38

Copyright (c) 2001 by The American Association for Thoracic Surgery

0022-5223/2001 \$35.00+ $0 \quad \mathbf{1 2 / 1 / 1 1 4 6 3 6}$

doi: $10.1067 / \mathrm{mtc} .2001 .114636$
Background: Recent studies suggest that viral interleukin 10 suppresses alloimmune response in transplantation and that cationic lipids are one of the most promising nonviral vehicles for gene therapy. The aim of this study was to examine the effect of ex vivo lipid-mediated viral $I L I O$ gene transfer into rat lung allografts on subsequent rejection.

Methods: Male F344 rats (RT1lvl) underwent left lung transplantation with allografts from Brown Norway rats (RT1n). Allografts were transvascularly transfected 15 minutes after harvest with $5 \mathrm{~mL}$ of 1:20-diluted (group $1, \mathrm{n}=7$ ) or 1:40-diluted (group 2, $\mathrm{n}=6$ ) GL67-pCMVievIL-10 complex. Group $3(\mathrm{n}=7)$, serving as the control group, received 1:40-diluted GL67-pCF1-chloramphenicol acetyltransferase complex. All allografts were preserved for 3 hours at $10^{\circ} \mathrm{C}$ before transplantation. In all groups recipients were killed on postoperative day 5. Transgene expression of viral interleukin 10 was assessed by means of both reverse transcriptase-polymerase chain reaction and immunohistochemistry. Histologic rejection score, allograft gas exchange, exhaled nitric oxide level, and allograft cytokine mRNA expression were also assessed.

Results: Dose-dependent transgene expression of viral interleukin 10 was detected by means of both reverse transcriptase-polymerase chain reaction and immunohistochemistry. Allograft gas exchange $\left(\mathrm{PaO}_{2}\right)$ in groups $1(114.06 \pm$ $61.1 \mathrm{~mm} \mathrm{Hg})$ and $2(108.58 \pm 35.7 \mathrm{~mm} \mathrm{Hg})$ was significantly better than that in group $3(66.4 \pm 8.22 \mathrm{~mm} \mathrm{Hg} ; P=.020$ and $P=.023$, respectively). The vascular rejection score in group 1 was significantly lower than that in group $3(P=.032$, Kruskal-Wallis test). Exhaled nitric oxide levels in group $2(5.150 \pm 6.38 \mathrm{ppb})$ were significantly lower than those in group $3(13.517 \pm 10.4 \mathrm{ppb} ; P=.039)$. Allograft interleukin 2 mRNA expression levels in group $1(1.123 \pm 0.23$ relative units) were significantly lower than those in group 3 (1.753 \pm 0.71 relative units; $P=.038$ vs group 3 ).

Conclusions: Lipid-mediated ex vivo viral ILIO gene transfer into rat lung allografts improved graft gas exchange, reduced histologic rejection scores, downregulated graft interleukin 2 mRNA expression, and reduced exhaled nitric oxide levels by postoperative day 5 . These results suggest a therapeutic potential of graft viral IL1O gene transfer as an effective immunosuppressive strategy against lung allograft rejection. 


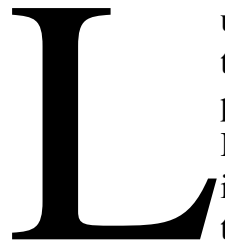

ung transplantation has evolved into an effective therapeutic option in the management of patients with end-stage pulmonary diseases. ${ }^{1}$ However, allograft rejection remains a serious impediment to the clinical success of lung transplantation. Gene transfer, the temporary introduction of genes to organs, which results in transient gene expression and production of a functional gene product to modify tissue responses, might be an effective strategy to decrease transplant rejection. Ex vivo gene delivery to grafts during cold storage before implantation might offer a specific opportunity for achieving graft-targeted, sustained, endogenous production of therapeutic gene products, while at the same time minimizing possible unwanted exposure to the transgene product of nontargeted organs. Gene transfer of immunosuppressive cytokine genes to the allograft may be a viable local immunosuppressive strategy by markedly impairing effective antigen presentation, reducing or eliminating immunogenicity, and preventing rejection or prolonging graft survival while avoiding the systemic toxicity of conventional immunosuppression.

Interleukin 10 (IL-10) is mainly produced by macrophages and $\mathrm{T}_{\mathrm{H}^{2}} 2$ cells. It inhibits the synthesis of cytokines by $\mathrm{T}_{\mathrm{H}} 1$ cells activated by monocyte/macrophage antigen-presenting cells. $^{2}$ It has been shown that IL-10 inhibits monocyte/macrophage-dependent T-cell activation and antigen presentation, ${ }^{3,4}$ as well as alloreactivity in vivo. ${ }^{5}$ Because of these effects, it has been suggested that IL-10 might be useful in the prevention of transplant rejection. Stimulatory effects of IL-10, however, have also been observed on both Tand B-cell differentiation, including enhancing major histocompatibility complex (MHC) class II expression on B cells. Viral IL-10 (vIL-10), a product encoded by the Epstein-Barr virus BCRF1 open-reading frame, is homologous to cellular IL-10, especially in the coding region of the mature protein sequence. ${ }^{6}$ It shares many biologic properties with cellular IL10 , including cytokine synthesis inhibitory activity and downregulation of class II MHC expression on monocytes. vIL-10, however, does not possess such costimulatory activities of cellular IL-10, ${ }^{7}$ which suggests that vIL-10 may be a more potent immunosuppressant molecule.

In the current study we examined the influence of lipidmediated viral ILIO gene transfer and overexpression within lung allografts on subsequent rejection in an MHC-mismatched strain combination.

\section{Material and Methods \\ Plasmids}

The plasmids pCMVievIL-10 and pCF1-chloramphenicol acetyltransferase (CAT) were kindly provided by Genzyme Corporation (Framingham, Mass). pCMVievIL-10 was constructed to encode the immunosuppressive cytokine vIL-10 under the control of the human cytomegalovirus immediate early promoter in the sense ori- entation. pCF1-CAT consists of the human cytomegalovirus immediate early gene promoter-enhancer CAT cDNA, as previously described. ${ }^{8}$ The sequence of vIL-10 was confirmed by DNA sequencing before use with the 377 DNA Sequencer (PE Applied Biosynthesis, Foster City, Calif). The bioactivity of pCMVievIL10 was confirmed by the in vitro functional assay, as reported previously, ${ }^{9}$ on the basis of the ability of IL-10 to inhibit the synthesis of interferon (IFN) $\gamma$ by phytohemagglutinin antigen P-stimulated human peripheral blood mononuclear cells. ${ }^{6}$

\section{Liposomal Vector}

Genzyme lipid 67 (Genzyme Corporation) is an amphiphile consisting of a hydrophobic lipid anchor group (cholesterol) linked to a positively charged spermine head group in a T-shaped configuration. Lipid 67/dioleylphosphatidylethanolamine in a molar ratio of 1:2 was supplied as dried films and kept at $80^{\circ} \mathrm{C}$, as previously described..$^{8}$ The dried lipid films were hydrated with sterile $4^{\circ} \mathrm{C}$ water, treated in a vortex, and kept at $4^{\circ} \mathrm{C}$ for 10 minutes. This homogeneous suspension was mixed with an equal volume of plasmid DNA and kept at $30^{\circ} \mathrm{C}$ for 15 minutes. The final concentrations were $1 \mathrm{mmol} / \mathrm{L}$ for the cationic lipid mixture and $4 \mathrm{mmol} / \mathrm{L}$ for the plasmid DNA. Immediately before the injection to the allografts, the complex solution was diluted into $5 \mathrm{~mL}$ of saline solution in a $1: 20$ or $1: 40$ ratio.

\section{Animals}

Male inbred Brown Norway and F344 rats, weighing 250 to $320 \mathrm{~g}$, were obtained from Harlan Sprague-Dawley (Indianapolis, Ind). All animal procedures were approved by the Animal Study Committee of Washington University. Animals received humane care in compliance with the "Guide for the Care and Use of Laboratory Animals" prepared by the Institute of Laboratory Animal Resources, National Research Council, and published by the National Academy Press, revised 1996.

\section{Study Design, Gene Transfer, and Transplantation}

Animals were divided into 3 groups. Transfection was accomplished with $5 \mathrm{~mL}$ of 1:20-diluted (group $1, \mathrm{n}=7$ ) or 1:40-diluted (group 2, $\mathrm{n}=6$ ) GL67-pCMVievIL-10 complex. Group $3(\mathrm{n}=7)$, serving as the control group, received 1:40-diluted GL67-pCF1CAT complex. Donor rat pulmonary arteries were flushed with 20 $\mathrm{mL}$ of cold $\left(4^{\circ} \mathrm{C}\right)$ saline solution after systemic heparinization. Heart-lung blocks were immediately excised en bloc and kept at $10^{\circ} \mathrm{C}$. The GL67-plasmid complex diluted in $5 \mathrm{~mL}$ of saline solution was injected into the allograft pulmonary vein retrograde through a $20-\mathrm{cm}$ polyethylene tube (internal diameter $0.38 \mathrm{~mm}$ ), with a pressure of $20 \mathrm{~cm} \mathrm{H} \mathrm{H}_{2} \mathrm{O}$ for 10 minutes. After storage in saline solution at $10^{\circ} \mathrm{C}$ for 3 hours, the grafts were flushed with cold $\left(4^{\circ} \mathrm{C}\right)$ saline solution to eliminate the remaining liposomeDNA complexes from the pulmonary vasculature. Left lung allografts were then orthotopically transplanted by means of a modification of the previously described cuff technique. ${ }^{10}$

\section{Assessment}

Recipient animals underwent median sternotomy on postoperative day 5. After crossclamping of the right main bronchus and pulmonary artery, allografts were ventilated with $100 \%$ oxygen $(1.5$ $\mathrm{mL}$ of tidal volume at a rate of 100 breaths/min). Peak airway pres- 
sures were measured, and exhaled gas was collected for 3 minutes. After 5 minutes of graft ventilation, arterial blood samples were obtained for blood gas analysis. Recipients were then killed, and left lung allografts were immediately flushed with $20 \mathrm{~mL}$ of cold saline solution. The lower half of the lung graft was frozen in liquid nitrogen and stored at $-80^{\circ} \mathrm{C}$ for reverse transcriptase-polymerase chain reaction (RT-PCR) assessment. The upper half of the graft was fixed with Histochoice fixative (AMRESCO, Solon, Ohio) flushed through the trachea with $20 \mathrm{~cm} \mathrm{H}_{2} 0$ for histologic assessment. These sections were stained with hematoxylin and eosin and examined by a pathologist (J.H.R.) blinded to the tissue group. The sections were graded separately for both acute vascular rejection and airway rejection on the basis of the revised working formulation, as described previously. ${ }^{11}$

\section{RNA Isolation and cDNA Synthesis}

Total lung RNA was prepared by means of guanidine isothiocyanate extraction with RNeasy Mini Kit (QIAGEN Inc, Valencia, Calif), according to the manufacturer's instructions. Extracted RNA was quantified by a spectrophotometer (Spectronic Genesys 5; Spectronic Instruments, Inc, Rochester, $\mathrm{NY}$ ). Each microgram of extracted RNA was reverse transcribed at room temperature for 10 minutes, $42^{\circ} \mathrm{C}$ for 15 minutes, $99^{\circ} \mathrm{C}$ for 5 minutes, and $5^{\circ} \mathrm{C}$ for 5 minutes in a total of $20 \mu \mathrm{L}$ of reaction mixture: $5 \mathrm{mmol} / \mathrm{L} \mathrm{MgCl}_{2} ; 50 \mathrm{mmol} / \mathrm{L} \mathrm{KCl} ; 10 \mathrm{mmol} / \mathrm{L}$ Tris-HCl ( $\mathrm{pH} \mathrm{8.3);1} \mathrm{mmol/L} \mathrm{of} \mathrm{each} \mathrm{deoxynucleotide} \mathrm{triphos-}$ phate, $1 \mu \mathrm{L}$ of RNase inhibitor, $2.5 \mathrm{U} / \mu \mathrm{L}$ cloned murine leukemia virus reverse transcriptase, and $2.5 \mu \mathrm{mol} / \mathrm{L}$ oligo $\mathrm{d}(\mathrm{T})_{16}$ (Perkin Elmer, Foster City, Calif).

\section{Semiquantitative PCR}

Reverse-transcribed cDNA was amplified by PCR with 0.01 to $0.03 \mathrm{U} / \mu \mathrm{L}$ Hot StarTaq Polymerase (QIAGEN Inc, Valencia, Calif) on a Mastercycler gradient (Eppendorf Scientific, Hamburg, Germany) in a $22-\mu \mathrm{L}$ reaction $(2.0 \mu \mathrm{L}$ of RT product, $1.5 \mathrm{mmol} / \mathrm{L}$ $\mathrm{MgCl}_{2}, 200 \mu \mathrm{mol} / \mathrm{L}$ of each deoxynucleotide triphosphate, and 0.3 to $0.5 \mu \mathrm{mol} / \mathrm{L}$ of each primer, PCR buffer [QIAGEN Inc, Valencia, Calif]), including $\mathrm{KCl}$, Tris- $\mathrm{HCl}$, and $\left(\mathrm{NH}_{4}\right)_{2} \mathrm{SO}_{4}$, after the first step of $95^{\circ} \mathrm{C}$ for 17 minutes, 25 to 35 cycles at $95^{\circ} \mathrm{C}$ for $30 \mathrm{sec}-$ onds, $58^{\circ} \mathrm{C}$ (annealing temperature varying for different primers) for 30 seconds, and $72^{\circ} \mathrm{C}$ for 1 minute, followed by a final incubation at $72^{\circ} \mathrm{C}$ for 10 minutes. The sense and antisense sequence of primer pairs was designed for glyceraldehyde-3-phosphate dehydrogenase, vIL-10, IL-2, tumor necrosis factor $\alpha$, inducible nitric oxide synthase (iNOS), IFN- $\gamma$, and endogenous IL-10.

PCR cycles and annealing temperature were calibrated for each primer pair. The glyceraldehyde-3-phosphate dehydrogenase bands were used to calibrate PCR input at unsaturated amplification for semiquantification. PCR products were electrophoresed on a $0.8 \%$ agarose gel and visualized by means of ethidium bromide staining. The gel images were stored by using the Gel Documentation System Image Store 7500 (version 7.12; UVP Inc, Upland, Calif) with a UV transilluminator. The average optical density of bands was quantitated by using the GelBase/GelBlotPro software (version 3.10; Syngene/Synoptics Ltd, Frederick, Md). Normal left lung samples of Brown Norway rats $(n=6)$ were also assayed in the same way as samples from the other groups for comparison.

\section{Immunohistochemistry for vIL-10}

Paraffin-embedded lung allograft sections were mounted on charged glass slides. After deparaffinization and hydration in graded ethanol, antigen retrieval was performed by means of steam treatment in Target Retrieval Solution (DAKO, Carpinteria, Calif) for 35 minutes at $95^{\circ} \mathrm{C}$. Blocking steps included Fc Receptor Blocker (Accurate Chemical \& Scientific Corp, Westbury, NY) and Super Block Blocking Buffer (PIERCE, Rockford, Ill) supplemented with $10 \%$ normal goat serum and $1 \%$ bovine serum albumin. All washes consisted of TBS $(100 \mathrm{mmol} / \mathrm{L}$ Tris and 500 $\mathrm{mmol} / \mathrm{L} \mathrm{NaCl}, \mathrm{pH} 7.4$ ) supplemented with $0.1 \%$ saponin and $0.2 \%$ Triton X-100, by using the R\&D Systems (Minneapolis, Minn) permeabilization protocol for cytokines.The immunohistochemistry procedure was enhanced with the Tyramide Signal Amplification kit (TSA-Indirect; NEN Life Science Products, Boston, Mass), according to the manufacturer's instructions. All steps were performed at room temperature. In brief, the slides were incubated overnight with biotinylated rat antiviral IL-10 mAb (1:25; Pharmingen, San Diego, Calif). After quenching endogenous peroxidase with $3 \% \mathrm{H}_{2} \mathrm{O}_{2}$ /phosphate-buffered saline solution for 15 minutes, the slides were incubated with streptavidin-horseradish peroxidase for 30 minutes, biotinyl tyramide solution for 25 minutes, and streptavidin-alkaline phosphatase for 30 minutes. Color development was performed with BCIP/NBT substrate (Vector Laboratories, Inc, Burlingame, Calif), including levamisole, $5 \mathrm{mmol} / \mathrm{L}$. Slides were counterstained with nuclear fast red and permanently mounted with Cytoseal 60 (Stephens Scientific, Kalamazoo, Mich).

\section{Exhaled Nitric Oxide Analysis}

Nitric oxide (NO) levels in allograft exhaled gas were measured with a Sievers $280 \mathrm{NO}$ analyzer (Sievers Instruments, Inc, Boulder, Colo) within 30 minutes of collection. Emissions from electronically excited nitrogen dioxide were detected in a gas-phase chemiluminescent reaction between NO and ozone. The sensitivity of the measurement is less than $1 \mathrm{ppb}$. At every measurement, it was confirmed that the baseline NO level of $100 \%$ oxygen was $0 \mathrm{ppb}$. Exhaled NO from normal left lungs of Brown Norway rats $(n=5)$ was also measured in the same way as that for the other study groups.

\section{Statistical Analysis}

Data were analyzed by means of 1-way analysis of variance and the Fisher post hoc multiple comparison test. Data not normally distributed were transformed with a square root or logarithmic transformation before performing the analysis of variance. Nonparametric data were analyzed with the Kruskal-Wallis test and the Mann-Whitney test with Bonferroni correction. All data are expressed as means $\pm \mathrm{SD}$.

\section{Results}

\section{Semiquantitative RT-PCR for Transgene vIL-10}

Semiquantitative RT-PCR for vIL-10 was performed to confirm allograft pCMVievIL-10 transfection at transcriptional levels. vIL-10 transgene mRNA expression in lung grafts was detected in all samples of groups 1 and 2. No vIL-10 mRNA was detected in group 3 (Figure 1). vIL-10 transgene mRNA 

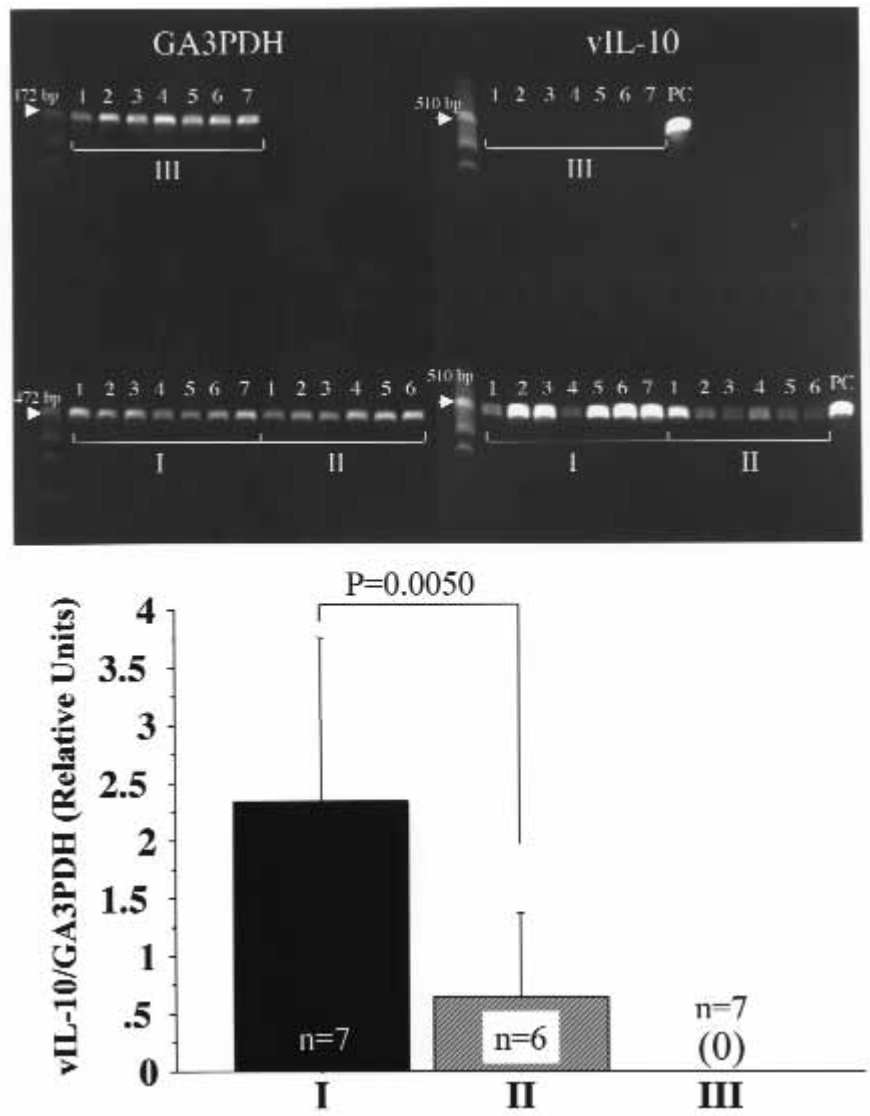

Figure 1. Semiquantitative RT-PCR analysis of vIL-10 mRNA transgene expression in rat lung allografts. The peak areas of bands were expressed as a relative ratio of vIL-10/glyceraldehyde-3-phosphate dehydrogenase (GA3PDH). The gel image shows vIL-10 bands from groups 1 and 2 but not from group 3. The relative ratio of vIL10/glyceraldehyde-3-phosphate dehydrogenase in group 1 was significantly higher than that in group $2(P=.0050$ vs group 2). Values are means $\pm S D$ of 6 or 7 animals per group. $P C$, Positive control.

expression (mean $\pm \mathrm{SD})$ in group 1 ( $2.33 \pm 1.44$ relative units) was significantly higher than that in group $2(0.637 \pm 0.74$ relative units; $P=.005)$. These results confirmed the presence of transgene vIL-10 expression in all lung allografts of groups 1 and 2 in a dose-dependent fashion.

\section{Immunohistochemistry for Transgene vIL-10}

Immunohistochemistry for vIL-10 was performed with sections prepared from paraffin-embedded tissues to confirm allograft pCMVievIL-10 transfection at translational levels. There was strong cytoplasmic staining in the majority of bronchial epithelial cells. No nuclear staining was observed. Positive staining in alveolar epithelial cells was also observed in both flattened type I cells and hub-like type II cells. The staining was more focal and was seen in approximately $25 \%$ of the alveolar epithelial cells. Alveolar macrophages also showed positivity in the cytoplasm. No staining was observed in endothelial cells, stromal cells, or lymphocytes within the perivascular cuffs (Figure 2). These findings demonstrate vIL-10 transfection to specific types of cells and local production of vIL-10 transgene protein within allografts. The staining was specific to transgene vIL-10 because we did not see any staining in group 3 .

\section{Histologic Rejection Score}

The vascular rejection score in group 1 was significantly lower than that in group $3(P=.032$, Kruskal-Wallis test). There were no significant differences between groups in histologic airway rejection grading (Figure 3 ). These results suggest that allograft vIL-10 overexpression could lead to major immunoalteration to the point at which histologic differences can be seen and lung allograft rejection is reduced.

\section{Lung Graft Function}

$\mathrm{PaO}_{2}$ (mean $\pm \mathrm{SD}$ ) levels in arterial blood obtained 5 minutes after right hilar crossclamping in groups 1 (114.06 \pm $61.1 \mathrm{~mm} \mathrm{Hg})$ and $2(108.58 \pm 35.7 \mathrm{~mm} \mathrm{Hg})$ were significantly higher than those in group $3(66.40 \pm 8.22 \mathrm{~mm} \mathrm{Hg}$; 

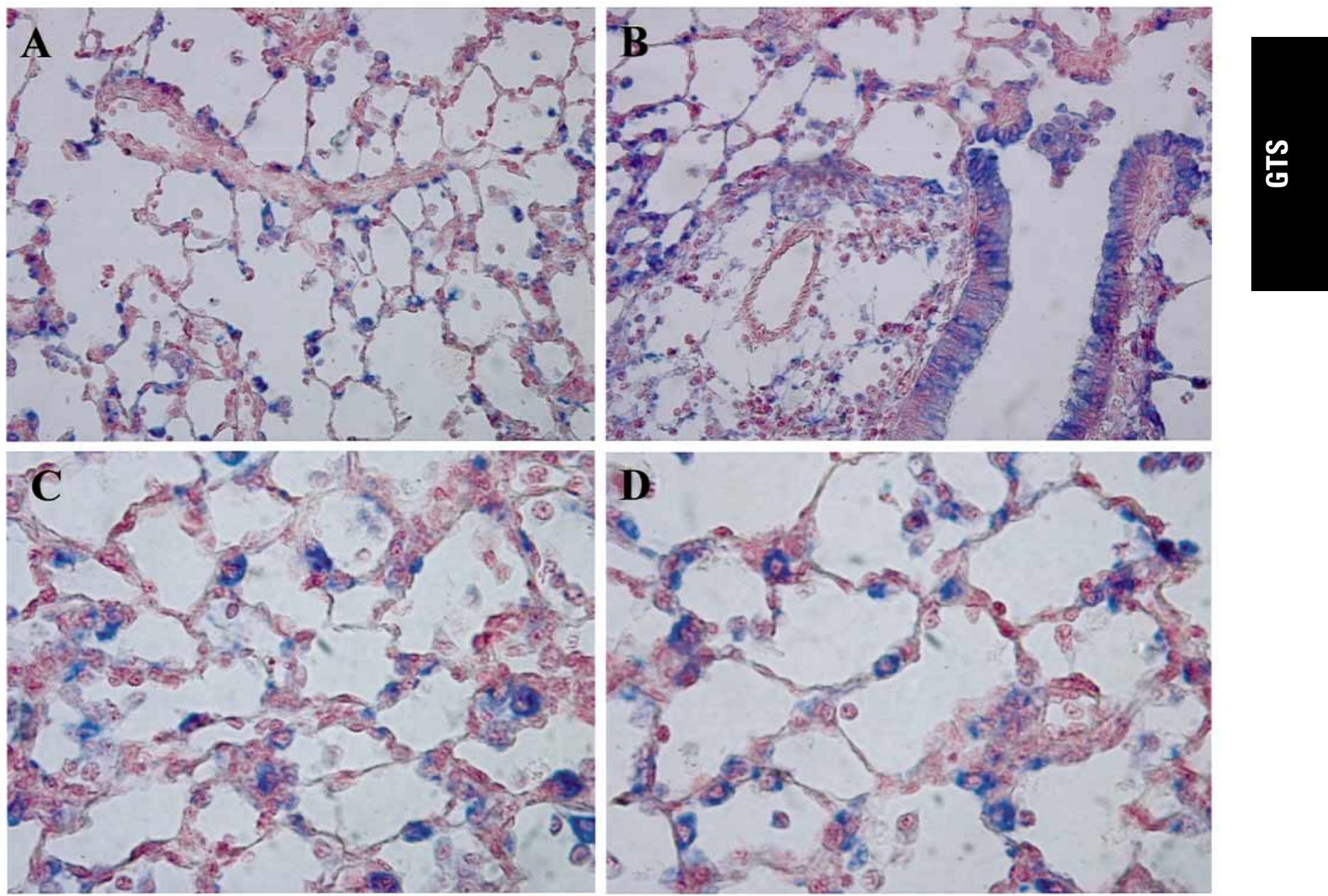

Figure 2. Immunohistochemistry for transgene vIL-10. Transgene vlL-10 protein was detected by means of immunohistochemistry in bronchial endothelial cells, alveolar epithelial cells, and alveolar macrophages. (Original magnifications: A, 200×; B, 200×; C, 400×; D, 400×.)

$P=.020$ and $P=.023$, respectively, vs group 3; Figure 4). There were no significant differences between groups in $\mathrm{PaCO}_{2}$ levels $(P=.82)$ and peak airway pressures $(P=.64)$. These data show that graft vIL-10 overexpression significantly improved graft lung function, suggesting the alleviation of allograft rejection.

\section{Exhaled NO Levels}

Exhaled NO levels (mean \pm SD) in group $2(5.150 \pm 6.38$ $\mathrm{ppb})$ were significantly lower than those in group 3 (13.517 $\pm 10.4 \mathrm{ppb} ; P=.039$ vs group 3 ), whereas exhaled NO levels from normal left lungs of Brown Norway rats $(0.00 \pm$ $0.00 \mathrm{ppb})$ were significantly lower than those in groups 1 and $3(P<.005$, respectively). There were no significant differences between groups 1 and $3(P=.49$, Figure 5$)$. These results indicate that local vIL-10 overexpression with only low-dose pDNA-lipid complex significantly suppresses exhaled NO levels. The results suggest that exhaled NO levels in normal lungs are low (and not detectable in this model) and that the upregulated exhaled NO levels in allograft rejection can be remarkably suppressed by graft vIL10 overexpression.

\section{Semiquantitative RT-PCR for Allograft Cytokine Expression}

Allograft IL-2 mRNA expression levels (mean \pm SD) in group $1(1.123 \pm 0.23$ relative units $)$ were significantly lower than those in group $3(1.753 \pm 0.71$ relative units; $P=$ .038 vs group 3 ), whereas IL-2 expression levels in group 2 $(1.181 \pm 0.74$ relative units) were also lower than those in group 3, trending toward the significant level $(P=.068$ vs group 3). Normal lung IL-2 expression levels $(0.666 \pm 0.23$ relative units) were significantly lower than those in group 3 $(P=.0014$ vs group 3 , Figure 6$)$. These results suggest that 

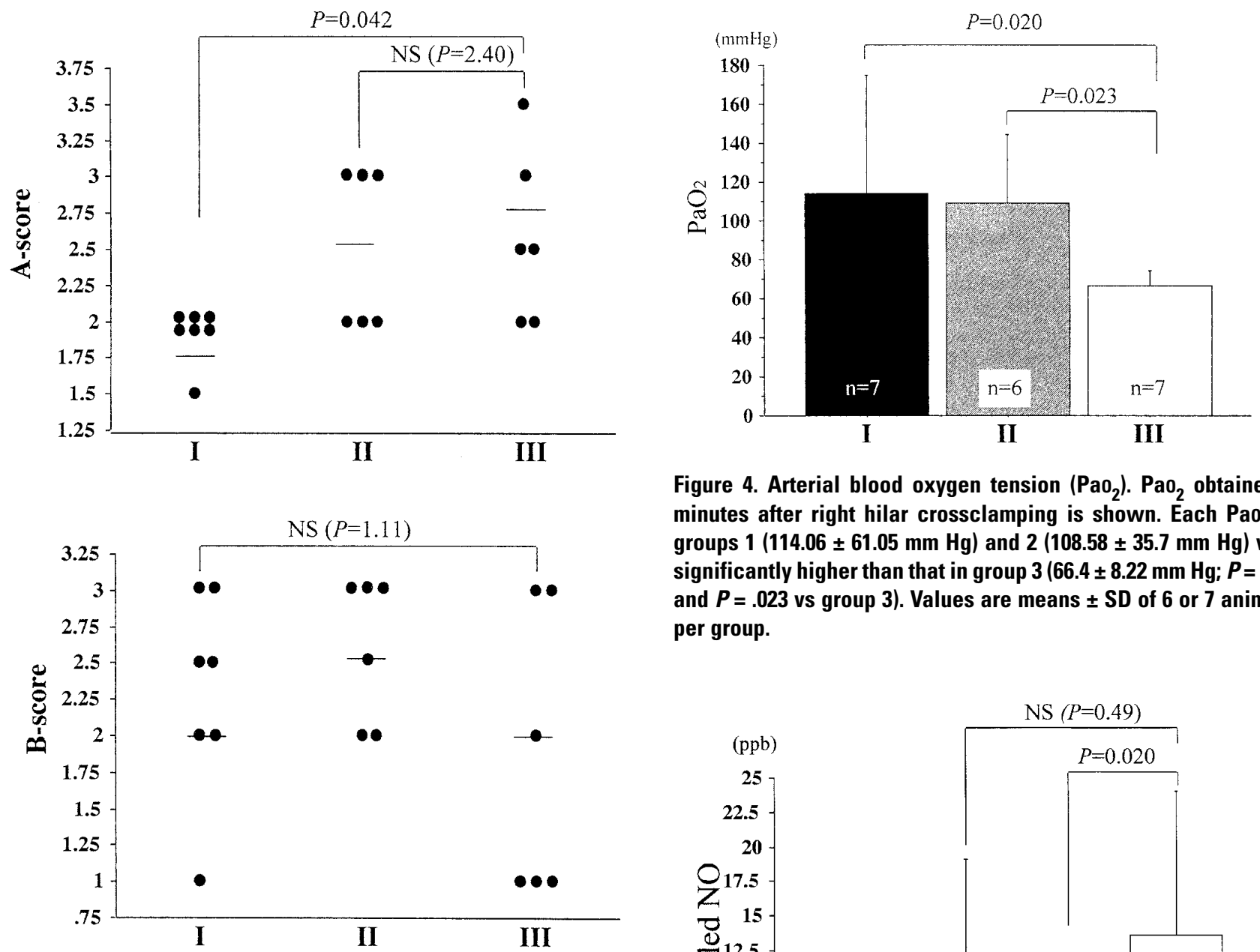

Figure 4. Arterial blood oxygen tension $\left(\mathrm{PaO}_{2}\right)$. $\mathrm{PaO}_{2}$ obtained 5 minutes after right hilar crossclamping is shown. Each $\mathrm{PaO}_{2}$ in groups $1(114.06 \pm 61.05 \mathrm{~mm} \mathrm{Hg})$ and $2(108.58 \pm 35.7 \mathrm{~mm} \mathrm{Hg})$ was significantly higher than that in group $3(66.4 \pm 8.22 \mathrm{~mm} \mathrm{Hg;} P=.020$ and $P=.023$ vs group 3). Values are means \pm SD of 6 or 7 animals per group.

Figure 3. Histologic rejection score. The sections were graded separately for both acute vascular rejection ( $A$-score) and airway rejection (B-score). The acute vascular rejection score in group 1 was significantly lower than that in group $3(P=.042$ vs group 3 , Kruskal-Wallis test). There were no significant differences (NS) in airway rejection scores. Bars show median values.

IL-2 mRNA expression levels are low in normal lungs and significantly upregulated during allograft rejection by day 5 . Furthermore, our data indicated that allograft IL-2 upregulation is significantly reduced by local vIL-10 overexpression.

Normal lung mRNA expression of tumor necrosis factor $\alpha$, iNOS, IFN- $\gamma$, and endogenous IL-10 was also significantly lower than that in other groups $(P<.05$, respectively), although no significant differences were observed between groups 1 and 3 or groups 2 and 3 (Figure 7). These findings suggest that mRNA expression of these cytokines was minimal in normal lungs and remarkably upregulated during allograft rejection by postoperative day 5 . However, graft vIL-10 overexpression in this model did not lead to any significant change in graft cytokine levels.

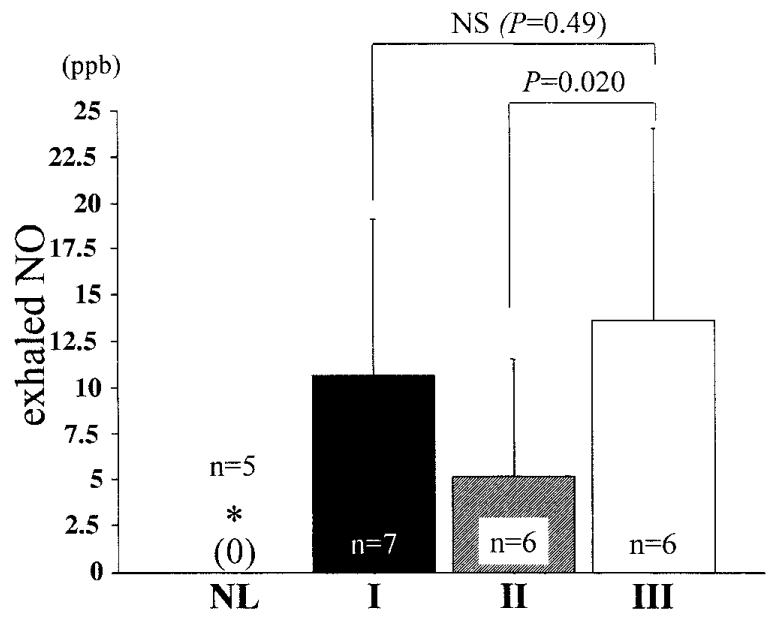

Figure 5. Exhaled NO levels from rat lung allografts. Exhaled NO levels in group $2(5.150 \pm 6.38 \mathrm{ppb})$ were significantly lower than those in group $3(13.517 \pm 10.4 \mathrm{ppb} ; P=.020$ vs group 3$)$. Exhaled NO levels in normal lungs ( $N L ; 0.00 \pm 0.0 \mathrm{ppb}$ ) were significantly lower than those in groups 1 and 3 ( $^{*}<.005$, respectively). Values are means $\pm S D$ of 5 to 7 animals per group.

\section{Discussion}

The present results demonstrated that lipid-mediated ex vivo viral ILIO gene transfer into rat lung allografts improved graft gas exchange, reduced histologic rejection scores, downregulated graft IL-2 mRNA expression, and reduced exhaled NO levels on post-transplantation day 5 in a model of BN-to-F344 lung allotransplantation. Several other studies have indicated that local vIL-10 production can suppress 

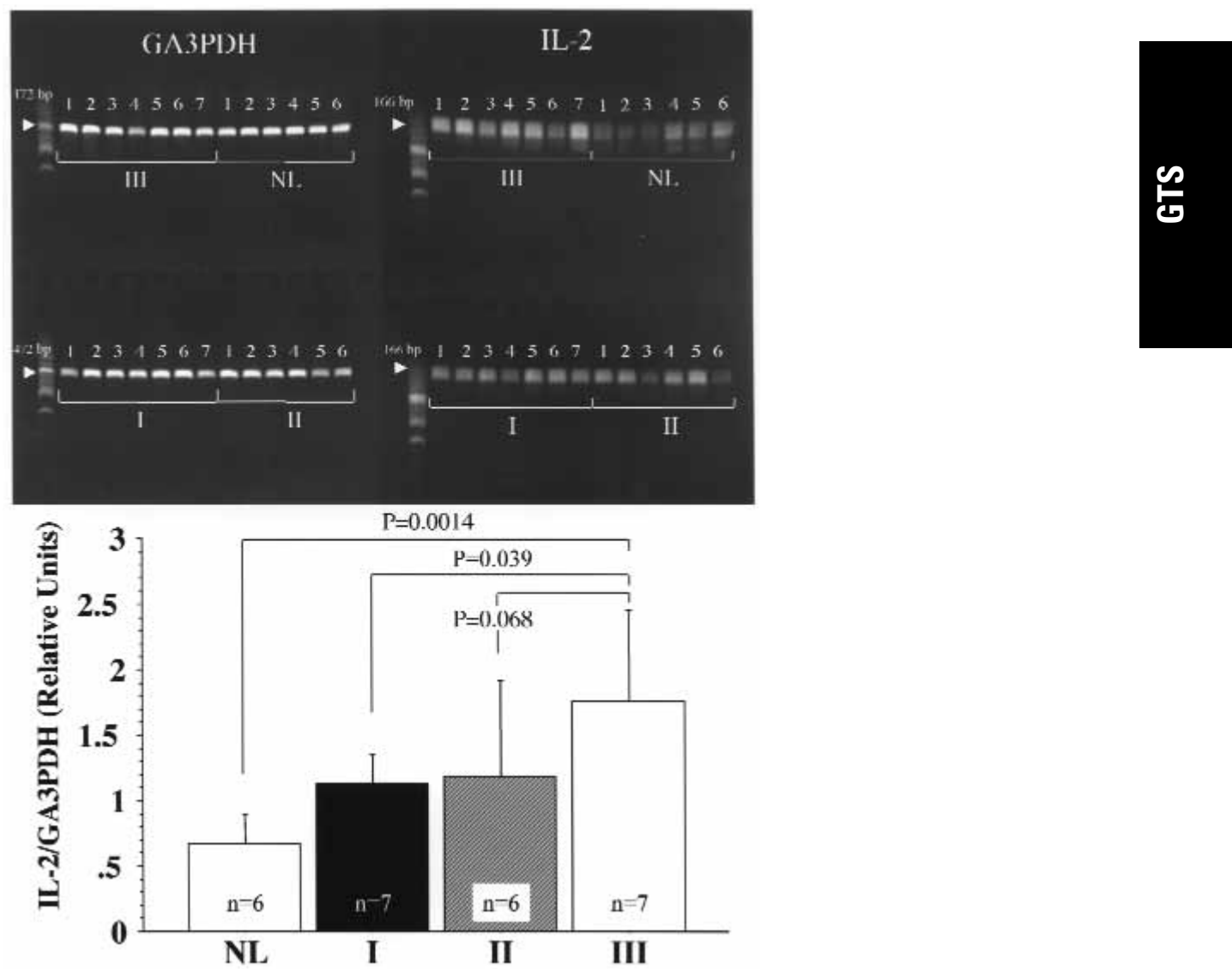

Figure 6. Semiquantitative RT-PCR analysis of IL-2 mRNA expression in rat lung allografts. The peak areas of the bands were expressed as the relative ratio of IL-2/glyceraldehyde-3-phosphate dehydrogenase (GA3PDH). IL-2 mRNA expression in group 1 and in normal lungs was significantly lower than that in group $3(\boldsymbol{P}=.039$ and $\boldsymbol{P}=$ .0014 vs group 3). IL-2 mRNA expression in group 2 was lower than that in group 3, trending toward significance $(P=.068$ vs group 3). Values are means \pm SD of 6 or 7 animals per group.

immune reactivity in response to alloantigen. Although some reports indicated detrimental effects ${ }^{12}$ or ineffectiveness ${ }^{13}$ of cellular IL-10, which possesses immunostimulatory activities on allograft rejection, retroviral or lipid-mediated gene transduction of vIL-10 prolonged graft survival when injected directly into cardiac allografts. ${ }^{14,15}$ Viral ILIO gene transfer also decreased allogenic lymphocyte proliferative response to cultured human islets. ${ }^{16}$ Consistent with these observations, the present data seem to show the significant efficacy of graft ex vivo viral ILIO gene transfer as a strategy for local lung-graft alloimmune suppression.

A diverse range of delivery vehicles is currently being assessed to facilitate gene transduction. These include recombinant replication-deficient viral vectors and cationic lipids, and both delivery systems possess certain advantages and disadvantages. Although adenovirus-mediated gene transfer is significantly more efficient than that afforded by cationic lipids, ${ }^{8}$ the recombinant viruses can be prone to inflammation and inactivation by the host immune sys- tem. ${ }^{17}$ Cationic lipids, one of the most promising nonviral vehicles, ${ }^{18}$ are less immunostimulatory. They are invariably composed of a hydrophobic lipid anchor group capable of forming liposomes and interacting with membranes linked to a positively charged head group that interacts with and perhaps condenses the pDNA. DNA-cationic lipid complexes also possess dose-dependent toxicity, especially when directly delivered to the lungs, which can be attributed to the detergent-like activity of the cationic lipid component ${ }^{19}$ or the immunostimulatory unmethylated $\mathrm{CpG}$ sequences harbored in plasmid DNA. ${ }^{20}$ Cationic lipids facilitate gene transfer through still poorly understood processes. This involves formation of a positively charged DNA-cationic lipid complex, adherence to the negatively charged cell membrane, endocytosis of the complex, release of DNA from the endosome into the cytoplasm, and translocation of DNA into the nucleus, leading to eventual gene expression. ${ }^{21}$ Optimized formulation of GL67 has been shown to be highly efficient and relatively less toxic for gene transfer 

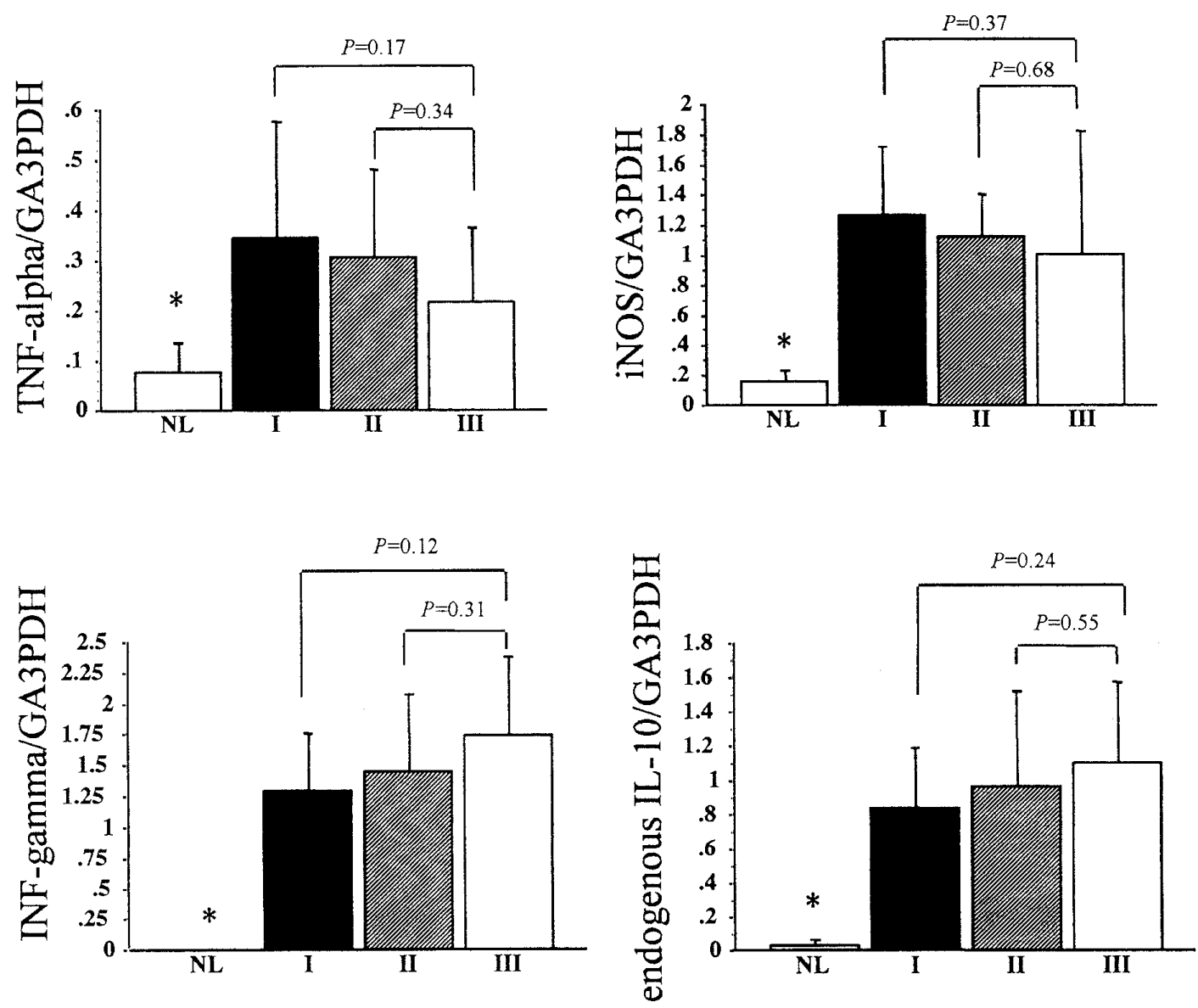

Figure 7. RT-PCR analysis for mRNA expression of tumor necrosis factor (TNF) $\alpha$, iNOS, IFN- $\gamma$, and endogenous IL10 in rat lung allografts. Normal lung (NL) mRNA expression in these cytokines was significantly lower than that in other groups $\left({ }^{*} P<.05\right.$, respectively). There were no significant differences between groups 1,2 , and 3 . Values are means \pm SD of 4 to 7 animals per group. GA3PDH, Glyceraldehyde-3-phosphate dehydrogenase.

to the lung and 100 times more active than the early generation cationic lipid. ${ }^{8}$ Our prior study of naked viral ILIO gene transfer with a BN-to-Lewis lung allograft rejection model could not exert substantial reduction of rejection, except for decreased graft expression of iNOS mRNA and suppression of exhaled NO9. The present GL67-mediated vIL-10 transfection attenuated allograft rejection, which may be attributable to the enhanced transfection efficiency of GL67 in comparison with DNA administered alone. ${ }^{22}$

In the current study the ex vivo GL67-mediated approach was used for a graft-targeted viral ILIO gene transfer. Our prior work on this method of gene transfer has suggested that gene transfer at low temperatures during graft storage yielded consistent and reproducible transgene expression, even with short storage times. ${ }^{23}$ With storage at $10^{\circ} \mathrm{C}$ for 1 hour, transgene CAT expression became detectable 4 to 6 hours after implantation, and significant levels were observed for at least 28 days. We and others have shown that lung allografts are rejected rapidly, between 4 and 6 days after transplantation in such an RT1-incompatible donorrecipient combination as $\mathrm{BN}$ to $\mathrm{F} 344 .{ }^{24,25}$ Thus, we expected that fulminant rejection would be present in control recipients if animals were killed on postoperative day 5 and that transgene expression might be achieved before the time of alloimmune reaction. Another study in our laboratory using the same approach also suggested that the optimum concentration of lipid-DNA complex is 100 or $200 \mu \mathrm{mol} / \mathrm{L}$ DNA for transfection without pulmonary toxicity. ${ }^{26}$ On the basis of these findings, we used the current concentration of lipid 67-DNA complex, storage temperature, and time.

In the current study allograft vIL-10 overexpression significantly suppressed intragraft IL-2 mRNA upregulation. In the rejection process IL-2, produced by activated T cells, promotes proliferation of $\mathrm{T}$ cells, leading to destruction of the allograft. Substantial evidence both from experimental and clinical studies has shown that IL-2 upregulation is 
associated with allograft rejection. Studies evaluating IL-2 mRNA from biopsy specimens in clinical cardiac transplants have demonstrated a strong association between IL-2 expression and histologic rejection. ${ }^{27,28}$ A number of immunosuppressive treatments, resulting in decreased production of IL-2 by graft-infiltrating cells, also allow prolongation of organ allografts. ${ }^{29}$ It has been reported that IL-10 directly inhibits human T-cell proliferation by specifically inhibiting IL-2 production at the transcriptional level when these cells are activated in an antigen-presenting, cell-independent manner. ${ }^{30}$ This is a direct effect of IL-10 on T cells mediated by their constitutively expressed IL-10 receptor. ${ }^{31}$ Florquin and colleagues ${ }^{32}$ have also shown that endogenous IL-10 induced by staphylococcal enterotoxin B in $\mathrm{CD}^{+}$ cells plays a cell-dependent immunoregulatory role in a model of $\mathrm{T}$ cell-dependent shock by downregulating IL-2 and IFN- $\gamma$ production. Put into the context of these studies, the present findings of significant suppression of intragraft IL-2 expression by vIL-10 suggest that reduced rejection can at least in part be attributed to the IL-2-suppressive effect of vIL-10.

The present results demonstrated the upregulation of exhaled NO levels in rejected allografts. We also observed suppression of exhaled NO levels with low-dose pDNAlipid complex but without suppression of iNOS mRNA on histologic allograft rejection. High-dose pDNA-lipid complex did not suppress exhaled NO levels but reduced the histologic allograft rejection. The exhaled NO level has become increasingly recognized as a noninvasive marker of acute lung allograft rejection. ${ }^{33}$ Upregulation of iNOS mRNA expression and increased production of NOS and NO during allograft rejection have been also demonstrated in many experimental and clinical transplantations, ${ }^{25,34}$ whereas increased immunosuppressive therapy has been able to restore these to normal levels. ${ }^{35}$ Our prior study of naked viral ILIO gene transfer with a BN-to-Lewis lung allograft rejection model demonstrated a direct correlation between high exhaled NO levels from rejected lungs and iNOS mRNA upregulation. ${ }^{9}$ In the current study, however, the effects of vIL-10 on allograft iNOS expression levels were not clear, and there was no positive correlation between these 2 parameters on postoperative day 5 , despite significantly suppressed exhaled NO levels with low-dose pDNA-lipid complex. These results may be attributed to the proinflammatory properties of liposome GL67/unmethylated pDNA complex, which can promote proinflammatory cytokine expression in a dose-dependent fashion, ${ }^{20}$ including IFN- $\gamma$. Given that exhaled NO levels reflect both iNOS upregulation and the net allograft rejection, as shown in above-mentioned studies, the present data may still support the notion that the vIL-10 immunosuppressive activity parallels iNOS/exhaled NO levels in acute lung rejection, whereas its suppressive effect on iNOS expression was obscured by proinflammatory properties of pDNA-lipid complex in a dose-dependent fashion.

This study has a number of potential limitations. Results might be different with alternate doses of plasmid or lipid vector. However, as noted above, these doses were selected after careful review of our own preliminary data and data from other reports. The ex vivo route of administration has proven effective, especially when transgene expression is not required at the time of transplantation. In addition, it is recognized that no matter how effective, gene transfer results in only temporary transgene expression. In this study the 5-day kill time was selected because in this major antigenic mismatch combination fulminant rejection with graft loss in untreated animals is known to occur 5 days after transplantation. Our hope was to affect this fulminant rejection. However, the endobronchial route of transfection provides the possibility of repeat administration in an effort to have a lasting effect on graft rejection.

In conclusion, the present study demonstrated that lipidmediated ex vivo viral IL10 gene transfer into rat lung allografts improved graft gas exchange, reduced histologic rejection score, downregulated graft IL-2 mRNA expression, and reduced exhaled NO levels by postoperative day 5 in a model of rat lung allotransplantation. These data strongly support the notion that lipid-mediated graft viral ILIO gene transfer may be an effective immunosuppressive strategy that may overcome acute lung allograft rejection.

We thank Richard B. Schuessler, $\mathrm{PhD}$, for statistical consultation; Paul J. Goodfellow, PhD, for assistance with gel image processing; Kathleen Grapperhaus, for experimental set-up; and Dawn Schuessler and Marry Ann Kelly for secretarial assistance.

\section{References}

1. Meyers BF, Lynch J, Trulock EP, Guthrie TJ, Cooper JD, Patterson GA. Lung transplantation: a decade of experience. Ann Surg. 1999;230:362-70.

2. de Waal Malefyt R, Abrams J, Bennet B, Figdor CG, de Vries JE. Interleukin-10 (IL-10) inhibits cytokine synthesis by human monocytes: an autoregulatory role of IL-10 produced by monocytes. $J$ Exp Med. 1991;174:1209-20.

3. Moorre KW, OíGarra A, de Waal Malefyt R, Viera P, Mosmann TR. Interleukin-10. Аnпи Rev Imunol. 1993;11:165-90.

4. Howard M, OíGarra A, Ishida H, de Waal Malefyt R, de Vries JE. Biological properties of interleukin-10. J Clin Immunol. 1992;12:23947

5. Delvaux A, Donckier V, Bruyns C, et al. Effects of systemic administration of rIL-10 in an in vivo model of alloreactivity. Transplantation. 1994;58:972-4.

6. Hsu DH, De Waal Malefyt R, Fiorentino DF, et al. Expression of interleukin-10 activity by Epstein Barr virus protein BCRF-1. Science. 1990;250:830-2.

7. de Waal Malefyt R, Haanen J, Spits H, et al. Interleukin-10 (IL-10) and viral IL-10 strongly reduce antigen-specific human $\mathrm{T}$ cell proliferation by diminishing the antigen-presenting capacity of monocytes via downregulating of class II major histocompatibility complex expression. J Exp Med. 1991;174:915-24.

8. Lee ER, Marshall J, Siegel CS, et al. Detailed analysis of structures and formulations of cationic lipids for efficient gene transfer to the lung. Hum Gene Ther. 1996;7:1701-17. 
9. Itano H, Wanjiang Zhang, Ritter JH, et al. Endobronchial transfection of naked viral interleukin-10 gene in rat lung allotransplantation. Ann Thorac Surg. 2000. In press.

10. Mizuta T, Kawaguchi A, Nakahara K, Kawashima Y. Simplified rat lung transplantation using a cuff technique. J Thorac Cardiovasc Surg. 1991;102:159-60.

11. Yousem SA, Berry GJ, Cagle PT, et al. Revision of the 1990 working formulation for the classification of pulmonary allograft rejection: Lung Rejection Study Group. J Heart Lung Transplant. 1996;15:1-15.

12. Qian S, Li W, Li Y, et al. Systemic administration of cellular interleukin-10 can exacerbate cardiac allograft rejection in mice. Transplantation. 1996;62:1709-14.

13. Lee MS, Wogensen L, Shizuru J, Oldstone MBA, Sarvetnick N. Pancreatic islet production of murine interleukin-10 does not inhibit immune-mediated tissue destruction. J Clin Invest. 1994;93:1332-8.

14. Qin L, Chavin KD, Ding Y, et al. Retrovirus-mediated transfer of viral IL-10 gene prolonged murine cardiac allograft survival. J Immunol. 1996;156:2316-23.

15. DeBruyne LA, Li K, Chan SY, Qin L, Bishop DK, Bromberg JS. Lipid-mediated gene transfer of viral IL-10 prolongs vascularized cardiac survival by inhibiting donor-specific cellular and humoral immune responses. Gene Ther. 1998;5:1079-87.

16. Benhamou PY, Mullen Y, Shaked A, Bahmiller D, Csete ME Decreased alloreactivity to human islets secreting recombinant viral interleukin-10. Transplantation. 1996;62:1306-12.

17. Yang Y, Li Q, Ertl HC, Wilson JM. Cellular and humoral responses to viral antigens create barriers to lung-directed gene therapy with recombinant adenovirus. $J$ Virol. 1995;68:2004-15.

18. Ledley FD. Nonviral gene therapy: the promise of genes as pharmaceutical products. Hum Gene Ther. 1995;6:1129-44

19. Scheule RK, St George JA, Bagley RG, et al. Basis of pulmonary toxicity associated with cationic lipid-mediated gene transfer to the mammalian lung. Hum Gene Ther. 1997;8:689-707.

20. Yew NS, Wang KX, Przybylska M, et al. Contribution of plasmid DNA to inflammation in the lung after administration of cationic lipid:pDNA Complex. Hum Gene Ther. 1999;10:223-34.

21. Zabner J, Fasbender AJ, Moninger T, Poellinger KA, Welsh MJ. Cellular and molecular barriers to gene transfer by a cationic lipid. $J$ Biol Chem. 1995;270:18997-9007.

22. Zabner J, Cheng SH, Meeker D, et al. Comparison of DNA-lipid complexes and DNA alone for gene transfer to cystic fibrosis airway epithelia in vivo. J Clin Invest. 1997;100:1529-37.
23. Boasquevisque $\mathrm{CH}$, Mora BN, Bernstein M, et al. Ex vivo liposomemediated gene transfer to lung isografts. $J$ Thorac Cardiovasc Surg. 1998;115:38-44.

24. Prop J, Nieuwenhuis P, Wildewuur CRH. Lung allograft in the rat. I. Accelerated rejection cause by graft lymphocytes. Transplantation. 1985;40:25-30.

25. Worrall $\mathrm{NK}$, Boasquevisque $\mathrm{CH}$, Botney $\mathrm{MD}$, et al. Inhibition of inducible nitric oxide synthase ameliorates functional and histological changes of acute allograft rejection. Transplantation. 1997;63:1095101.

26. Nagahiro I, Mora BN, Boasquevisque CHR, Scheule RK, Patterson GA. Toxicity of cationic liposome-DNA complex in lung isografts. Transplantation. 2000;69:1802-5.

27. Baan CC, van Emmerik NEM, Balk AHMM, et al. Cytokine mRNA expression in endomyocardial biopsies during acute rejection from human heart transplants. Clin Exp Immunol. 1994;97:293-8.

28. Cunningham DA, Dunn MJ, Yacoub MH, Rose ML. Local production of cytokines in the human cardiac allograft. A sequential study. Transplantation. 1994;57:1333-7.

29. Granelli-Piperno A. Lymphokine gene expression in vivo is inhibited by cyclosporin A. J Exp Med. 1990;171:533-44.

30. de Waal Malefyt R, Yssel H, de Vries JE. Direct effects of IL-10 on subsets of human CD4+ T cell clones and resting T cells: specific inhibition of IL-2 production and proliferation. $J$ Immunol. 1993;150:4754-65.

31. Liu Y, Wei SH, Ho S, de Waal Malefyt R, Moore KW. Expression cloning and characterization of a human interleukin-10 receptor. $J$ Immunol. 1994;152:1821-9.

32. Florquin S, Amraoui Z, Abramowicz D, Goldman M. Systemic release and protective role of IL-10 in staphylococcal enterotoxin B-induced shock in mice. J Immunol. 1994;153:2618-23.

33. Mora BN, Boasquevisque CHR, Uy G, et al. Exhaled nitric oxide correlates with experimental lung transplant rejection. Ann Thorac Surg. 2000;69:210-5

34. Yang X, Chowdhury N, Cai B, et al. Induction of myocardial nitric oxide synthase by cardiac allograft rejection. J Clin Invest. 1994;94:714-21.

35. Benvenuti C, Bories PN, Loisance D. Increased serum nitrate concentration in cardiac transplant patients. A marker for acute allograft cellular rejection. Transplantation. 1996;61:745-9. 